\title{
On the Meaning of Fermi's Paradox
}

\section{Carl L. DeVito}

Key Words: Calculus of variations, Euler-Lagrange equation, Fermi paradox.

\begin{abstract}
One of the few pieces of hard data that we have in connection with SETI is embodied in Fermi's famous question, often stated simply as: Where is everyone? Our purpose here is to show that this "paradox" is telling us something about the number of communicating societies in the galaxy and the rate at which such societies "grow". Our analysis is based on a mathematical technique that is of fundamental importance in a number of areas of physics.
\end{abstract}

Introduction: In 1950, during a lunch time conversation in which extraterrestrials were discussed, the physicist Enrico Fermi turned to his colleagues, Edward Teller, Emil Konopinski and Herbert York, and asked "Don't you ever wonder where everybody is?'[1, p. 12]. The paradoxical nature of this question stems from the fact that although most scientists believe that technologically sophisticated societies exist in the Milky Way galaxy, in over 60 years of searching, we have not detected any. Many "solutions" to this paradox have been offered [4]. Some depend on assumptions about the nature of alien societies and/or what the members 
of such societies will and will not do. Such speculation is useful but must be viewed with great caution. We quote the anthropologist Steven Gould:

“I must confess that I simply don't know how to react to such arguments. I have enough trouble predicting the plans and reactions of people closest to me. I am usually baffled by the thoughts and accomplishments of humans in different cultures. I'll be damned if I can state with certainty what some extraterrestrial source of intelligence might do."

In this paper we will make no assumptions about the nature of alien societies or about the possible actions of the members of such societies. The Fermi paradox may be pointing to a more fundamental phenomenon.

\section{Setting up the Problem}

To begin we follow Drake and take $\mathrm{N}$ to be the number of civilizations in the galaxy whose electro-magnetic emissions are detectable but, rather than thinking of $\mathrm{N}$ as a steady-state, as is often done in deriving the Drake equation, we will take $\mathrm{N}$ to be a function of time; new societies arise and some die out, so $\mathrm{N}=\mathrm{N}(\mathrm{t})$. At some point the first of these societies arose. We will take this to be time zero and we will take the number of these societies, it may be only one or, perhaps several may have arisen simultaneously, to be $\mathrm{N}(0)$. In this area, where our knowledge is so limited, 
we think it wise to keep our analysis as simple as possible, and we shall do so throughout the paper.

Suppose, as a thought experiment, we had conducted a programmed scan of the entire galaxy, at many frequencies, for some period of time, say $\Delta \mathrm{t}$. Suppose further, that the program was set up so that each detection of an alien society was simply noted and the search continued. We would expect the rate at which societies were detected to depend on their number, $\mathrm{N}(\mathrm{t})$, and on the rate at which this number changes, $\mathrm{N}^{\prime}(\mathrm{t})$. Thus this rate should be some unknown function of these two quantities, say $\mathrm{R}\left(\mathrm{N}, \mathrm{N}^{\prime}\right)$. So the number of societies detected would be $\mathrm{R}\left(\mathrm{N}, \mathrm{N}^{\prime}\right) \Delta \mathrm{t}$. Had we been scanning the galaxy in this way continuously, since time zero up to the present, time $\mathrm{p}$, the number of societies we would have detected would be

(1) $\int \mathrm{R}\left(\mathrm{N}, \mathrm{N}^{\prime}\right) \mathrm{dt}$ where the limits on the integral are from 0 to $\mathrm{p}$.

Now, of course, we have not been scanning the galaxy continuously, but if (1) were a large number we would expect to have detected some societies by now. The Fermi paradox seems to be telling us that this number is small. Not zero, but minimal. The reader will recall that the calculus of variations was created to find the extremes of integrals of the type (1). This technique plays a central role in 
mechanics, (Hamilton's principle [2, p. 81]), and also in optics (Fermat's principle $[2, \mathrm{p} .93])$

\section{Solving the Problem}

The extremes of (1) are found by solving the Euler-Lagrange equation:

$$
\text { (2) } \partial \mathrm{R} / \partial \mathrm{N}-\mathrm{d} / \mathrm{dt}\left[\partial \mathrm{R} / \partial \mathrm{N}^{\prime}\right]=0 \quad[2, \mathrm{p} .41]
$$

The Fermi paradox seems to be telling us that $\mathrm{N}(\mathrm{t})$ is among the many solutions to equation (2). We recall that the general solution to a partial differential equation is extremely difficult, usually impossible, to find and, even if found, it is seldom useful; because it involves arbitrary unknown functions rather than constants [5; p.3]. What one does is combine the equation with an additional condition and seek a particular solution that satisfies that condition. We don't have an additional condition here. So we seek the simplest solution we can find in the hope that it will shed some light on the paradox.

We know we can find particular solutions by separating the variables [3, p.587] so we set $\mathrm{u}=\mathrm{N}^{\prime}$, to simplify the notation, write $\mathrm{R}(\mathrm{N}, \mathrm{u})=\mathrm{G}(\mathrm{N}) \mathrm{H}(\mathrm{u})$ and carry out the differentiation.

(3) $\mathrm{G}^{\prime}(\mathrm{N}) \mathrm{H}(\mathrm{u})-\mathrm{d} / \mathrm{dt}\left[\mathrm{G}(\mathrm{N}) \mathrm{H}^{\prime}(\mathrm{u})\right]=0$ 
(4) $\mathrm{G}^{\prime}(\mathrm{N}) \mathrm{H}(\mathrm{u})-\left[\mathrm{G}(\mathrm{N}) \mathrm{H}^{\prime \prime}(\mathrm{u}) \mathrm{du} / \mathrm{dt}+\mathrm{H}^{\prime}(\mathrm{u}) \mathrm{G}^{\prime}(\mathrm{N}) \mathrm{u}\right]=0$

(5) $\mathrm{G}^{\prime}(\mathrm{N})\left[\mathrm{H}(\mathrm{u})--\mathrm{H}^{\prime}(\mathrm{u}) \mathrm{u}\right]--\left[\mathrm{G}(\mathrm{N}) \mathrm{H}^{\prime \prime}(\mathrm{u}) \mathrm{du} / \mathrm{dt}\right]=0$

(6) $\mathrm{G}^{\prime}(\mathrm{N}) / \mathrm{G}(\mathrm{N})=\mathrm{H}^{\prime \prime}(\mathrm{u}) \mathrm{du} / \mathrm{dt} /\left[\mathrm{H}(\mathrm{u})--\mathrm{H}^{\prime}(\mathrm{u}) \mathrm{u}\right]$

Equation (2) is valid for all $\mathrm{N}$ and all $\mathrm{N}^{\prime}$ and so in equation (6), where on side depends only on $\mathrm{N}$ and the other only on $\mathrm{N}^{\prime}$, we treat them as independent variables. This means that each side is equal to a constant $\mathrm{k}$, and each choice of $\mathrm{k}$ gives us solutions [3, p.588].

To find $\mathrm{N}$ we need only work with the second equation in (6).

(7) $\mathrm{H}^{\prime \prime}(\mathrm{u}) \mathrm{du} / \mathrm{dt}+\mathrm{k}[\mathrm{uH}(\mathrm{u})-\mathrm{H}(\mathrm{u})]=0$

We may expand $\mathrm{H}$ in a series of powers of $\mathrm{u}$, but we notice two things. First, including higher and higher order terms, powers of $\mathrm{N}^{\prime}$, is assuming more precision than we should in connection with a problem in SETI. Next, because of the presence of the second derivative the first power of $u$ that gives a solution is $u^{2}$. Other solutions are possible (see the appendix) but we believe we should keep things as simple as we can.

Placing $H(u)=u^{2}$ (a coefficient will only divide out) in equation (7) yields

(8) $2 \mathrm{du} / \mathrm{u}^{2}=--\mathrm{kdt}$ hence

(9) $\mathrm{u}=2 /[\mathrm{kt}-\mathrm{c}]$ 
Here $\mathrm{c}$ is a constant of integration. Recalling that $\mathrm{u}=\mathrm{N}^{\prime}$ we integrate again to find that

$$
\mathrm{N}(\mathrm{t})=(2 / \mathrm{k}) \ln (\mathrm{kt}-\mathrm{c})+\mathrm{c}_{1}
$$

At time zero $\mathrm{N}$ is the constant $\mathrm{N}(0)$. Recalling that $\ln 1=0$ we see that $\mathrm{c}=--1$ and $\mathrm{c}_{1}=\mathrm{N}(0)$. Thus we have

$$
\mathrm{N}(\mathrm{t})=(2 / \mathrm{k}) \ln (\mathrm{kt}+1)+\mathrm{N}(0)
$$

There are other approaches to the problem, but the one above is the one we found most tractable.

The function $\mathrm{N}(\mathrm{t})$ must depend on the average time societies continue to communicate; the L in the original Drake equation. This is the only constant we have in connection with alien societies. If $\mathrm{L}$ is very long we would expect $\mathrm{N}$ to steadily increase. If $\mathrm{L}$ is short, $\mathrm{N}$ may vary widely. The constant $\mathrm{k}$ is arbitrary, by setting it equal to $\mathrm{L}$ we obtain a solution for $\mathrm{N}$ that may help explain the lack of success of our searches so far:

$$
\mathrm{N}(\mathrm{t})=(2 / \mathrm{L}) \ln (\mathrm{Lt}+1)+\mathrm{N}(0)
$$


It seems that the Fermi paradox is telling us that after the initial appearance of detectable societies, $\mathrm{N}(0)$, their number grows but, because of the logarithm, very slowly.

Remark 1. In connection with SETI, a subject where our knowledge is meager and uncertain, it is important not to read too much into our models. This is true of the original Drake equation where many of the terms are unknown, and L represents the average time a society remains detectable; a number we can only guess at! Equation (12) must be viewed with the same caution. Obtaining it, as we saw above, was a tricky process. It is only one possible solution to the Fermi paradox, but a very thought provoking one.

Remark 2. The author would like to thank the reviewers for their helpful suggestions. Reviewer 1's comments were especially insightful, and I'd like to thank him, or her, for suggesting areas for future research. 


\section{References}

1. DeVito, Carl L. (2014). Science, SETI and Mathematics. New York: Berghahn Books.

2. Kot, Mark. (2014). A First Course in the Calculus of Variations. Providence, Rhode Island: American Mathematical Society.

3. Kreyszig, Erwin. (1999). Advanced Engineering Mathematics. New York: John Wiley \& Sons, Inc.

4. Webb, Stephen. (2002). Where is Everybody? New York: Copernicus Books.

5. Berg, Paul W. and McGregor, James L. (1969). Partial Differential Equations. San Francisco: Holden-Day.

Appendix: One of the reviewers asked to see the calculations involved when one takes $\mathrm{H}(\mathrm{u})$ to be a polynomial. These get rapidly very difficult. To see this we need only consider the simple case $\mathrm{H}(\mathrm{u})=\mathrm{u}^{2}+\mathrm{u}^{3}$. The analogue of equation (8) is then 
$\left[(2+6 u) /\left(u^{2}+2 u^{3}\right)\right] d u=--k d t$

Expanding the integrand via partial fractions we can integrate to obtain

$2 \ln (\mathrm{u})-2 \ln (1+2 \mathrm{u})-2 / \mathrm{u}=--\mathrm{kt}+\mathrm{c}$.

One can see that it is difficult to obtain $u$ from this. 